\title{
A Aplicação dos Princípios da Cooperação Hídrica Internacional e da Precaução na Gestão das Águas Subterrâneas
} Transfonteiriças: O Caso do Aqüuifero Guarani $^{1}$

\author{
Laura Martins Miller
}

\section{Introdução:}

A Otganização das Nações Unidas (ONU) elegeu simbolicamente o ano de 2003 como o Ano Intemacional da Água Doce, reconhecendo que a escassez de água vem sendo sentida em muitas regióes do planeta, apontando a água como o bem mais precioso do século XXI e preconizando a sua falta para o consumo humano como o principal problema ambiental do milênio. ${ }^{3}$

Neste quadro, a importância da cooperação entre os países que compartitham águas subterrâneas é inegável porque da quantidade de água doce disponível na Terra,

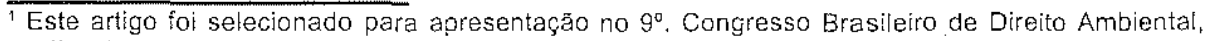
realizado em São Paulo, no periodo de 31 de malo a 03 de junho de 2004. Agradeço especialmente ao Professor Antônio Herman Benjamin, que assistiu a esta apresentação na University of Texas at Austin, nos Estados Unidos da América, incentivando prontamente a sua publicação. Agradeço também à Profa. Dra. Cláudia Lima Marques pela oportunidade de publicar o mesmo artigo nos Cadernos do Programa de Pós-Graduação da Universidade Federa! do Rio Grande do Sul (PPGDir. / UFRGS).

${ }^{2}$ Acadêrnica de Direito da Universidade Federal do Rio Grande do Sul. Pesquisadora do grupo de pesquisa "CNPq- Mercosul e Direito do Consumidor", orientado pela Profa. Dra. Claudia Lima Marques. Ex-bolsista FIPSE/CAPES participante do Consórcio em Educação Superior Brasil/ EUA sobre "Responsabilidade Ambiental" na Pace University of New York School of Law.

${ }^{3}$ Freitas, Fabiana Paschoal de. Águas Subterrâneas Transfonteiriças: O Aqüifero Guarani e o Projeto do GEF/Banco Mundial, In: Direito, Agua e Vida/ Law , Water and The Web of Life. Org: Benjamin, Antonio Herman, São Paulo: Imprensa Oficial, 2003, Vol. 2, p.159-171.
} 
A Aplicação dos Princípios da Cooperação Húdrica Internacional e cla Precaução na Gestão das Águas Subterrâneas Transtonteiriças: $\bigcirc$ Caso do Aquitifero Guarani

somente $1,2 \%$ apresenta-se sob a forma de rios e lagos; os $98,8 \%$ restantes constituem águas subterrâneas. ${ }^{4}$

Assim, não se pode olvidar o relevante valor das águas subterrâneas, que representam a quase totalidade do volume de água doce do planeta, excluídas as geleiras e calotas polares ${ }^{5}$, razão pela qual é apontada por Vladimir Passos de Freitas como a "fonte de abastecimento preferida. Elas apresentam maior facilidade de exploração, baixo custo e boa qualidade. Situam-se nos aqüíferos, que podem ser: solo, rocha ou sedimento permeável, capaz de armazenar água subterrânea". ${ }^{6}$

Com efeito, os aqüíferos são menos vulneráveis à poluição do que as águas superficiais, mas se contaminados, são necessários muitos anos para teverter a situaçăo, que nem sempre é possível, pois nâo detêm a capacidade de depuraçăo dos rios e da água do mar.

$O$ presente estudo analisa os princípios que regem a cooperação hídrica internacional e o princípio da precaução para demonstrar a sua aplicação prática no Projeto de Proteção Ambiental e Gestão Sustentável Integrada do Sistema Aqüífero Guarani.

Nesta lógica, o trabalho está dividido em 02 partes:

$1^{\circ}$ ) análise de princípios gerais de Direito Internacional bem assim do princípio da precaução, todos aplicáveis à cooperação hídrica em matéria de águas subterrâneas;

$2^{\circ}$ ) demonstração do estágio atual desta cooperação entre os países do Mercosul, con a análise da potencial harmonização legislativa em matéria de águas subterrâneas entre Brasil, Argentina, Uruguai e Paraguai, países que abrigam o Aquúfero Guarani, un dos maiores reservatórios de água subterrânea do mundo.

\section{Princípios Aplicáveis à Gestão de Águas Subtertâneas} Transfonteitiças: Cooperação Hídrica Internacional e Precaução

A progressiva carência de água implica a necessidade de melhorar o aproveitamento dos recursos hídricos através de uma gestăo integrada entre os países nos quais se situam as bacias hidrográficas compartilhadas. Por sua vez, a integração hídrica entre os países inclui a observância de princípios gerais de Direito Internacional.

\footnotetext{
${ }^{4}$ Rebouças, Aldo da Cunha. Águas Subterraneas. In: Rebouças, Aldo da Cunha; Braga, Benedito; Tundisi, José Galizia. Águas Doces no Brasil: capital ecologico, uso e conservação. São Paulo: Escrituras, 1999. p.01-37

${ }_{5}^{5}$ Fedeli, Claudia Cecilia. Responsabitidade Penal por Contaminação de Águas Subterrâneas. In: Direito, Água e Vida/ Law, Water and The Web of Life. Org: Benjamin. Antonio Herman, São Paulo: Imprensa Oficial, 2003, Vol. 1, p. 425-438

${ }^{6}$ Freitas, Vladimir Passos de. Águas: Consideraçōes Gerais. In: Águas: Aspectos Juridicos e Ambientais. Org: Freitas, Vladimir Passos de. Curitiba: Juruá Editora, 2002, p.23.
} 
a. O Princípio da Cooperação Hídrica Internacional: a Convenção das Nações Unidas sobre a Utilização dos Cursos de Água Internacionais para Fins Distintos da Navegação e o Bellagio Draft Treaty

O Direito Internacional das águas doces conta, atualmente, apenas com tratados de cooperação bilaterais e multilaterais para o âmbito específico de certas bacias hidrográficas. Entretanto, a Comissão de Direito Internacional da ONU trabalhou vinte e um anos na elaboração de um projeto de artigos sobre o Direito de Utilização dos Cursos de Água Internacionais para Fins Distintos da Navegação que, em 1997, foi aprovado por 103 países na forma de Convenção, a qual foi adotada e aberta à adesão, através da Resolução 51/226, aos 21.05.1997?, mas ainda não está em vigor, porque depende de mais ratificações ao seu texto.

Em 1989, um novo projeto de convenção é concluído: o Bellagio Draft Treaty $^{8}$, o qual também não se encontra em vigor, porque não submetido a assinaturas. Em que pese ainda sem força vinculativa, esta é a primeira codificação geral sobre águas subterrâneas.

Preparado por um grupo independente de especialistas internacionais, o Bellagio Draft Treaty consiste em um projeto completo de vinte artigos comentados e baseados em princípios e mecanismos que os Estados podem adotar para gerenciar as águas subterrâneas transfonteiriças. $\mathrm{O}$ artigo II, que trata dos seus objetivos gerais, prevê que "as partes reconhecem o seu interesse e responsabilidade comuns em assegurar o desenvolvimento razoável e eqüitativo bem como a administraçăo das águas subterrâneas nas áreas fronteiriças tendo em vista o bem estar geral de seus povos". ?

O Bellagio Draft Treaty é, pois, um importante modelo de convenção que inclui regras procedimentais e mecanismos institucionais para o uso racional, proteção e gerenciamento de águas subterrâneas transfonteiriças. $O$ projeto reflete a crença de um grupo multidisciplinar de especialistas em recursos hídricos no sentido de agregar os aqǘf́reros aos esforços de gestão integrada das águas. Este entendimento, baseado na antecipação, no planejamento e na precaução é relevante porque, em geral, os Estados adotam uma postura reacionária e não preventiva em relação aos danos a estes recursos. ${ }^{10}$

Neste contexto, a Convenção das Naçóes Unidas e o Bellagio Draft Treaty codificam o costume internacional no tratamento das águas doces, superficiais e subterrâneas.

\footnotetext{
7 Aprovada por 103 votos a favor, 27 abstenções e 3 votos contrários (Burund, China e Turquia) (Maurizio Arcari, // Regime Giuridico delle Utifizzazioni dei Corsi d'Acqua Internazionali, p. 08) ${ }^{8} \mathrm{http} / /$ www ana.gov.br/guarani/gestao/gest tratados.htm. Acesso em 02.09.2003

๑ Tradução livre. O texto original em inglês diz: "the parties recognize their common interest and responsibility in ensuring the reasonable and equitable development and management of groundwaters in the border region for the well-being of their Peoples." Artigo If, parágrafo 1.

so McCaffrey, Stephen. The Law of International Watercourses. Oxford University Press, 200t, $p$. $427-428$.
} 
A Aplicação dos Princípios da Cooperação Hídrica Intemacional e da Precatição na $4: 15$ Gestão das Águas Subterrâneas Transfonteiriças: $O$ Caso do Aquífero Guarani

A primeira diretriz da cooperação internacional encon trada em ambos é a utilização eqüitativa e razoável do curso de água. $\mathrm{O}$ art. $5^{\circ}$ da Convenção de 1997 e 0 art. $2^{\circ}$. do Bellagio Draft Treaty a prevê:

\section{"Art. 50:}

Os Estados de um curso d'água devem participar no uso, desenvolvimento e proteção de um curso d'água internacional de forma eqüitativa e razoável. "Tal participação inclui tanto o direito de utilizar o curso d'água quanto a obrigação de coopetar na proteção e no desenvolvimento, como previsto nesta Convenção."

Freqüentemente, a própria natureza do conflito implica que um Estado năo considere o uso d'água, por outro Estado, como eqüitativo ou razoável. ${ }^{11}$ Assim, os parâmetros para que a aplicação da utilização eqüitativa e razoável não caia no subjetivismo e na indeterminação estão no art. $6^{\circ}$ da Convenção de 1997.

"Art. 6\%:

A utilização de maneira eqüitativa e razoável de um curso de água de conformidade con o art. 5․ requer que se tenham em conta todos os fatores e circunstâncias pertinentes, entre outros:

(a) geografia, hidrografia, hidrologia, clima, ecologia e outros fatores de caráter natural;

(b) as necessidades sociais e econômicas do Estados;

(c) a população dependente do curso d'água em cada Estado;

(d) os efeitos do uso dos cursos d'água em um Estado sobre um outro;

(c) usos existentes e potenciais do curso d'água;

(f) conservação, proteção, desenvolvimento e economia do uso dos recursos hidricos do curso d'água e os custos das medidas tomadas para aquele efeito;

(g) a disponibilidade de alternativas, de valor comparável, para um uso particular planejado ou existente". 12

As regras da Convenção das Nações Unidas já são consideradas parte integrante do Direito Internacional. A Corte Intemacional de Justiça, sediada em Haia, no caso "Gabcíkovo-Nagymaros"'3, em 1997, menciona o art. 5․, §2․ da Convenção ao considerar que a Eslováquia (antigamente Tcheco-Eslováquia), ao tomar unilateralmente o controle de um recurso compartilhado e, ao privar a

\footnotetext{
Thio, Amando Gallo Yamm. Aspectos Juridico-Ambientais da Utilização dos Cursos d'Água Internacionais. In: Direito, Água e Vida/ Law, Water and The Web of Life. Org: Benjamin, Antonio Herman, São Paulo: Imprensa Oficial, 2003, Vol. 2, p. 51-70.

12 Filho, Armando Gallo Yahin. Aspectos Juridico-Ambientais da Utilização dos Cursos d'Água Internacionais. In: Direito, Água e Vida/ Law, Waler and The Web of Life. Org: Benjamin, Antonio Herman, São Paulo: Imprensa Oficial, 2003, Vol. 2, p. 51-70.

${ }^{13}$ http://www icj-cil.orgl. Acesso en 28,08.2003.
} 
Hungria de seu direito a uma parte eqüitativa e razoável dos recursos naturais do rio Danúbio, não respeitou a proporcionalidade exigida pelo Direito Internacional. ${ }^{14}$

A segunda medida para cooperação em matéria de recursos hídricos é a comunicação entre os Estados, que inclui os deveres de notificação e informação, ambos já previstos nos Príncípios 18 e 19 da Declaração do Rio, elaborada na Conferencia sobre Meio Ambiente e Desenvolvimento realizada pela ONU no Brasil, Rio de Janeiro, em 1992:

18. "Os Estados notificarão imediatamente outros Estados acerca de desastres naturais ou outras situações de emergência que possam vir a provocar súbitos efeitos prejudiciais sobre o meio ambiente destes últimos. Todos os esforços serão enviados pela comunidade intemacional para ajudar os Estados afetados".

19. "Os Estados devem prover, oportunamente, a Estados que possam ser afetados, notificação prévia e informaçöes relevantes sobre atividades potencialmente causadoras de considerável impacto transfonteiriço negativo sobre o meio ambiente, e devem consultar-se com estes täo logo possivel de boa-fé". ${ }^{15}$

Estes deveres estão previstos no art. $9^{9}$. da Convenção de $1997^{16}$ e nos artigos $2^{\circ}$. e 3․ do Bellagio Draft Treaty. ${ }^{\prime ?}$

Por fim, o dever dos Estados de não causar danos transfonteiriços também é princípio norteador desta cooperação. Esta obrigação surgiu como uma forma de garantir a utilização de um curso de água internacional por parte de um Estado de forma soberana em seu território, e ao mesmo tempo, impedir que este uso acarrete danos, tais como assoreamento e contaminação. $O$ princípio 02 da Declaração do Rio' ${ }^{15}$ á a aftrma, bem assimo art. $7^{\circ}$. da Convenção da ONU.19

\footnotetext{
$\$ 4$ Machado, Paulo Affonso Leme. Recursos Hidricos: Direito Brasileiro e Internacional. Malheiros Editores, São Paulo, p. 134. Tanzi, Attila \& Arcari, Maurizio, The United Nations Convention on the Law of international Watercourses, at 96 (Kluwer Law International, 2001 ).

${ }^{15}$ Filho, Armando Gallo Yahin. Aspectos Juridico-Ambientais da Utilização dos Cursos d'Água internacionais. In: Direito, Água e Vida/ Law, Water and The Web of Life. Org: Benjamin, Antonio Herman, Săo Paulo: Imprensa Oficial, 2003, Vol. 2, p. 51-70.

${ }^{16}$ Artigo 9: Intercâmbio regular de dados e informação. "1. De conformidade com o art. 8, os Estados do curso d'água trocarão regularmente os dados e as informações que estão facilmente disponiveis sobre a situação do curso d'água, em particular as de caráter hidrológico, metereológico, hidrológico e ecológico, bem como as relativas à qualidade da água, assim como as previsões correspondentes. 2. Estado do curso d'água ao qual outro Estado do curso d'água solicite informaçỏes fará o possivel para prestá-las, mas poderá exigir que o Estado solicitante pague os custos razoáveis da compilação, processamento de dados e informações. 3. Os Estados do curso d’água farão o possivel para reunir e processar os dados e as informações de maneira que se facilite a sua utilização pelos Estados do curso d'água a que se destinam."

17 "2. Basin States shall consult and exchange relevant avallable information and data at the request of any one of them a) for the purpose of preserving the groundwaters of the basin from degration and protecting from impairment the geologic strucutre of the aquifer, including recharge areas; $b$ ) for the purpose of considering joint or parallel quality standards and environmental protection measures applicable to international grounwaters and their aquifers. 3. Basin States shall cooperate, at the request of any one of them for the purpose of collecting and analyzing additional needed information and data pertinent to the international groundwaters or their aquifers."
} 
A Aplicação dos Princípios da Cooperação Hídrica Intemacional e da Precaução na 417 Gestão das Águas Subterrâneas Transfonteiriças: O Caso do Aquiúfero Guararai

Questionou-se como solucionar os casos em que o uso do recurso é eqüitativo e razoável, no entanto, o Estado provoca um dano transfonteiriço. A leitura dos artigos $7^{\circ}$., item 2, e 10, item $1^{20}$, indica que o uso, por si só, não é infrator do Direito Internacional mesmo causando um dano transfonteiriço significativo. Porém, este uso deve ser considerado equiitativo e razoável e as partes envolvidas devem ter procedido a consultas entre si sobre o problema.

Visto a conteúdo do princípio da cooperação hídrica, resta delimitar as áreas de sua aplicação.

Há diferentes teses sobre a abtangência de um rio ou bacia internacional onde se aplica a cooperação hídrica entre os Estados. Conforme a adoção de uma ou de outra num tratado ou convenção internacional, os resultados podem gerar maior ou menor responsabilidade de um ou mais Estados.

A tese da bacia de drenagem internacional surgiu em 1966, e é hoje a mais aceita entre os países. Em reunião da Intemational Law Association, elaborou-se um conjunto de regras relativas à utilização de águas de rios internacionais, que ficaram conhecidas como Regras de Helsinque. Segundo este documento, "uma bacia de drenagem internacional é uma área geográfica que cobre dois ou mais Estados determinada pelos limites fixados pelos divisores de águas, inclusive as águas de superficie e as subterrâneas, que desembocam num ponto final comum." Esta teoria leva em consideração o ciclo hidrológico ${ }^{21}$. Assim, as águas em estados gasoso (ar atmosférico) e sólido (geleiras e calotas polares) também se incluem no conceito de bacia de drenagem, uma vez que estas águas, ao se liquefazerem, juntam-se aos rios da bacia e trazem consigo todo o volume de poluição que contêm. A importância fundamental que pode ser extraída deste contexto diz respeito à extensão do tegime de soberania múltipla aos rios que, apesar de estarem exclusivamente em território de úm único Estado, pertencem a uma bacia internacional e, portanto, devem ser tratados como se internacionais fossem. ${ }^{22}$

Esta tese foi adotada pela União Européia. A Diretiva 2000/60/CE do Parlamento Europeu prevê: "Os Estados-Membros garantirão que uma bacia hidrográfica que abranja o território de mais de um Estado-Membro seja incluída numa regiāo hidrográfica intemacional".

¡8 "Os Estados têm (...) o direito soberano de explorar seus próprios recursos (...) e a responsabilidade de garantir que as atividades sob sua jurisdição ou seu controle não causem danos ao meio ambiente de outros Estados".

${ }^{19}$ Art. $7^{\circ}$. 1. Os Estados ribeirinhos devem, ao utilizarem um curso d'água internacional em seus territórios, tomar todas as medidas apropriadas para prevenir danos significativos a outro Estado ribeirinho. 2. Quando um dano significativo, contudo, é causado a outro Estado do curso d'água, os Estados cujo uso cause tal dano devem, na ausência de um tratado sobre tal uso, tomar as medidas apropriadas, tendo em vista os preceitos dos artigos $5^{\circ}$. e $6^{\circ}$. em consulta ao Estado afetado, para eliminar ou diminuir o dano e, quando apropriado, discutir questões relativas à compensação.

${ }^{20}$ Art. 10. 1. Salvo acordo ou costume em contrário, nenhum uso de um curso d' água internacional tem em si a prioridade sobre os outros usos."

${ }^{21}$ Calasans, Jorge Thierry. Poluição dos Grandes Aquiferos e a Soberania Nacional: o exemplo da cooperação entre os Estados Unidos e o México. In: Anais do $5^{\circ}$. Congresso Internacional de Direito Ambiental, Imprensa Oficial, São Paulo, 2001, p. 448-457.

22 Fitho, Armando Gallo Yahin. Aspectos Juridico-Ambientais da Utilização dos Cursos d'Agua Internacionais. In: Direito, Agua e Vidal Law, Water and The Web of Life. Org: Benjamin, Antonio Herman, São Paulo: Imprensa Oficial, 2003, Vol. 2, p. 51-70. 
A Europa, portanto, adota um regime de soberania múltipla sobre os rios que atravessam diversos países e sobre os seus afluentes, mesmo que estes se restrinjam ao território de apenas um país. Normas comunitárias evitam que Estados situados à jusante de um rio sejam prejudicados pelo uso irresponsável das águas por parte daqueles que se situam à montante do mesmo curso hídrico. ${ }^{23}$

Com a assinatura do Tratado da Bacia do Prata, em 1969, Brasil, Argentina, Uruguai e Paraguai acordaram em adotar a tese da bacia de drenagem internacional. Assim, os afluentes principais e secundários de um rio internacional são considerados igualmente como internacionais - mesmo se estiverem situados inteiramente em território de um só país. Isso coloca grande parte dos rios das regiōes sul e sudeste do Brasil sobre o regime de soberania compartilhada, porque rios da Bacia da Prata, mesmo que se encontrem inteiramente no territónio brasileiro, são afluentes de rios internacionais, sendo, então, considerados internacionais.

Entretanto, a Comissão de Direito Intemacional da ONU rejeitou a terminologia bacia de drenagem internacional, conceituando, em no art. $2^{\circ}$. da Convenção sobre o Direito dos Usos dos Cursos de Água para Fins Distintos da Navegação, curso de água internacional como um "sistema de águas de superfície e de águas subterrâneas, constituindo, pelo fato de suas relações físicas, um conjunto unitário, terminando num ponto de chegada comum (art. 20. "b")." 24

Note-se que, pelas definições supra aludidas, a diferença fundamental entre a teoria adotada pela Comissão de Direito Internacional da ONU e a teoria da bacia de drenagem internacional reside no fato de a segunda considerar, além do sistema de águas que se constitui através de uma relação física, também o ciclo hidrológico..$^{25}$

Conforme a definição adotada pela Convenção para o termo 'curso de água intemacional', McCaffrey leciona que os princípios emanados da Convenção direcionam-se tanto às águas superficiais como às subterrâneas. Entretanto, alguns princípios devem ser aplicados de maneira mais rigorosa no âmbito das águas subterrâneas. Especialmente o dever de não causar danos transfonteiriços (artigo 7) merece mais atenção dos Estados que abrigam águas subterrâneas, uma vez que as mesmas movimentam-se lentamente e quando contaminadas podem levar anos ou gerações até a sua purificarão total. Da mesma forma, o princípio da comunicação entre os Estados, principalmente a função de avaliar e antecipar os possíveis impactos que podem advir da utilização da água, também ganha relevância. A razão é simples: os impactos acarretados pela poluição são menos visíveis nas águas subterrâneas do que nas superficiais, ${ }^{26}$

\footnotetext{
${ }^{23}$ Idem supra 21, p. 59.

${ }^{24}$ Machado, Paulo Affonso Leme. Recursos Hidricos: Direito Brasileiro e Internacional. Malheiros Editores, São Paulo, p. 127-128.

${ }^{25}$ Idem supra 21, p. 58.
} 
A Aplicação dos Princípios da Cooperação Hídtica Internacional e da Precaução na Gestão das Águzs Subterrâneas Transfonteiriças: $\bigcirc$ Caso do Aquiúfero Guarani

b. O Princípio da Precaução:

Nesta abstração inicial sobre os fundamentos estruturantes de princípios de Direito Internacional, ilustrar-se-á também as bases do princípio da precaução para, logo após, delimitá-lo no âmbito da gestão de águas subterrâneas no Mercosul.

A Declaração do Rio de Janeiro de 1992, votada pela Conferência das Naçóes Unidas, prevê expressamente que os Estados devem observar o princípio da precaução. ${ }^{27}$ Assim, sempre que houver perigo da ocorrência de um dano grave ou irreversível, a ausência de certeza científica absoluta não deverá ser utilizada como razão para se adiar a adoção de medidas eficazes, a fim de impedir a degradação ambiental. ${ }^{28}$

Quanto à tipologia do risco ou do perigo, Paulo Affonso Leme Machado ensina que os mesmos "serão analisados conforme o setor que puder ser atingido pela atividade. Por exemplo, a Convenção da Diversidade Biológica não exige que a ameaça seja 'séria ou irreversível', mas que a ameaça seja 'sensível', quanto à possivel redução ou perda da diversidade biológica. Ameaça sensível é 'aquela revestida de perceptibilidade ou aquela considerável ou apreciável.' A ConvençãoQuadro sobre a Mudança de Clima refere-se à ameaça de danos 'sérios ou irreversíveis'. A seriedade no dano possível é medida pela sua importância ou gravidade. A irreversibilidade no dano potencial pode ser entendida como a impossibilidade de volta ao estado ou condição anterior (constatado o dano, não recupera o bem atingido)",29

A doutrina norte-americana, por exemplo, desdobra o princípio em, pelo menos, quarto elementos cuja delimitação dependerá também das circunstâncias do caso concreto. Teoricamente, o primeiro destes elementos é o nível do risco que justifica a atuação preventiva (precautionary action). Um segundo consiste no tipo de ação a ser tomada quando a ameaça atinge o nível de risco de dano ambiental. Além disso, o princípio da precaução permite um balanço dos custos e benefícios de uma determinada ação antes de invocar os meios preventivos (precautionary action) para evitá-la. Finalmente, outro

\footnotetext{
${ }^{26}$ McCaffrey, Stephen. The Law of International Watercourses. Oxford University Press, 2001, p. 430431.

${ }^{27}$ Principio 15: "De modo a proteger o meio ambiente, o ptincípio da precaução deve ser amplamente observado pelos Estados, de acordo com suas capacidades. Quando houver ameaça de danos sérios ou irreversiveis, a ausência de absoluta certeza científica não deve ser utilizada como razão para postergar medidas eficazes e economicamente viáveis para prevenir a degradação ambiental". Tradução livre. O texto em inglês diz: "In order to protect the environment, the precautionary approach shall be widely applied by States according of their capabilities. Where there are threats of serious or irreversible damages, lack of full scientific certainty shall not be used as a reason to postponing cost-effective measures to prevent environmental degradation".

${ }^{28}$ Leile, José Rubens Morato. Dano Ambiental: do individual ao coletivo extrapatrimonial. Editora Revista dos Tribunais, 2000, p. 47.

${ }^{29}$ Machado, Paulo Afonso Leme, Direito Ambiental Brasileiro, 11ed., Matheiros Editores, 2003, p. 65.
} 
elemento é o nível de incerteza da ocorrência do dano, ou seja, se falta de certeza pode evitar a atuação preventiva (precautionary action). ${ }^{30}$

Oprincípio da prevenção, tal como o da precaução, busca instrumentos ou remédios antecipatórios contra o dano ambiental. Entretanto, observa-se que o primeiro exige que os perigos comprovados sejam eliminados. Já o princípio da precaução determina que a açäo para eliminar possíveis impactos danosos ao ambiente seja tomada antes de um nexo causal ter sido estabelecido con evidencia científica absoluta. ${ }^{31}$

Neste contexto, o princípio da precaução consiste em dizer que "não somente somos responsáveis sobre o que nós sabemos, sobre o que nós deveríamos ter sabido, mas, também, sobre o que nós deveriamos duvidar", conforme bem assinala Lavieille. ${ }^{32} \mathrm{O}$ princípio da precaução fornece, pois, uma indicação sobre as decisóes a tomar nos casos en que os efeitos sobre o meio ambiente de uma determinada atividade náo sejam plenamente conhecidos sob o plano científico. ${ }^{33}$

Contudo, na abalizada lição de Rehbinder, o princípio da precaução tem sido objeto de severas críticas especialmente devido à dificuldade de precisar o seu exato conteúdo, tendo sido mais invocado do que colocado em prática. ${ }^{34}$

No caso de potencias danos às águas subterrâneas, a enorme dificuldade de acesso a tal recurso acarreta, em princípio, a inexistência de considerável evidência científica acerca da ameaça. Isto gera, por sua vez, entraves à avaliação segura do risco de degradação dos aqǘferos advindo da poluição de águas superficiais ou da descarga de resíduos perigosos no solo.

\section{A Cooperaçăo Hídrica no Mercosul:}

Analisados os seus fundamentos, investigar-se-á a prática dos princípios da cooperação hídrica e da precaução no âmbito do Mercado Comum do Sul.

\footnotetext{
30 Katz, Deborah, The mismatch between the biosafety protocol and the precautionary principle, 13 Georgetown International Environmental Law Review, 949, Summer, 2001. Traduçäo livre. O texto em inglês diz: "The principle can be broken into several different elements to examine its effects. One element is the level of risk that justifies precautionary action. A second element is what action shouid be taken when a situation triggers this level of risk and uncertainty. The precautionary principle may also be examined to determine whether it allows a balancing of the risks and benefits of a certain action or situation before invoking precautionary means. Finally, another element is the level of scientific certainty or perhaps stated more clearly, whether a consensus, but lack of certainty, can be used to avoid precautionary action."

${ }^{31}$ Aragão, Maria de Fátima de Sousa. O principio do poluidor-pagador: pedra angular da politica comunitária do ambiente. Coimbra Editora, 1997, p.68 (Studia Ivridica, 23).

${ }^{32}$ Lavielle, Jean-Marc. Droit International de l'Énvrionment. Paris, Ellipses, 1998. Apud: Machado, Paulo Afonso Leme, Direito Ambiental Brasileiro, 11ed., Malheiros Editores, 2003, p. 64.

${ }^{33}$ Sul principio precauzionale nell Diritto Internazionale dell'Ambiente, Rivista di Diritto Internazionale LXXV/699-705, fasc. 3, Milão, Giuffrè Editore, 1992. Apud: Machado, Paulo Afonso Leme, Direito Ambientaf Brasileiro, 11ed, Malheiros Editores, 2003, p. 58.

${ }^{34}$ Rehbinder, Eckard and Stewart, Richard. Environmental protection policy: legal integration in the United States and the European Community. New York: De Gruyter, 1988
} 
A Aplicação dos Princípios da Cooperação Húdrica Intennacional e da Precaução na Gestão das Águas Subterrâneas Transfonteiriças: $O$ Caso do Acqüfero Guarani

a. Justificativas para a Implantação de uma Política Ambiental em Matéria de Águas no Mercosul:

O incremento comercial derivado do estabelecimento do Mercosul atua como incentivo para aumentar a produção de mercadorias em cada um dos Estadospartes. A conseqüência natural consiste em uma intensificação da utilização dos recursos naturais para incrementar dita produção.

Neste sentido, na constituição do Mercado Comum do Sul, o Tratado de Assunção, em seu artigo 1@. prevê o compromisso de os Estados harmonizarem suas legislações nas áreas que fortalecem o processo de integração. Assim, a necessidade de cooperação em matéria de águas ficou mais evidente por vários motivos.

Primeiro, porque a divergência na política ambiental de águas adotada pelos Estados-membros de um mercado comum pode desestruturar princípios como o da concorrência, isto é, um país ribeirinho pode colocar obstáculos à livre circulação das mercadorias através de seus rios.

Em segundo lugar, o Tratado de Assunção coloca entre os objetivos da criação do Mercado Comum a melhoria das condiçōes de vida de seus habitantes. Isso inclui o acesso à água para suprir necessidades básicas da população.

Além disso, a poluição de um curso de água compartilhado pode gerar efeitos danosos para os países transfonteiriços. ${ }^{35}$

Por fim, os princípios da cooperaçāo internacional e da precaução em matéria de tecursos hídricos podem ser implementados mais facilmente no contexto de um processo de integração regional, já que o mesmo supõe a pré-existência de estruturas supranacionais de cooperação. Estas servem como plataformas para colocar em prática os deveres e direitos de cada país em relação à utilização dos recursos hídricos compartilhados. ${ }^{36}$

b. O Projeto de Proteção Ambiental e Gestão Sustentável Integrada do Sistema Aqüífero Guarani:

Atualmente, os países do Mercosul, que abrigam um dos maiores mananciais de água subterrânea do mundo - o Aqüífero Guarani -, sinalizam a aplicação prática dos princípios de Direito Ambiental Internacional já analisados bem como de uma política ambiental em matéria de águas subterrâneas transfonteiriças.

\footnotetext{
35 Jimenez, Martha Lucia Olivar. O Estabelecimento de uma Politica Comum de Proteção do Meio Ambiente- sua necessidade num Mercado Comum. In: Estudos da Integração, $7^{\circ}$. Volume, Associação Brasileira de Estudos da Integração, Brasilia, 1994, p. 16-33.

${ }^{36}$ Iza, Alejandro. Desafios para la conservación de los recursos hidricos en los procesos de integración. In: Direito, Água e Vida/ Law, Water and The Web of Life. Org: Benjamin, Antonio Herman, São Paulo: Imprensa Oficial, 2003, Vol. 1, p. 33.
} 
O termo "Aqüifero Guarani" foi a denominação formal e unificadora atribuída, em 1994, pelo geólogo uruguaio Danilo Anton em homenagem à população indígena que ali habitava nos primórdios da colonização.

Antes de ganhar a sua atual denominaçăo, o Aqüífero já foi chamado de Aqǘffero Gigante do Mercosul - por se estender pelos Estados-membros do teferido acordo comercial - e era conhecido pelos nomes Botucatu no Brasil, Missiones no Paraguai e Tacuarembó no Uruguai e Argentina. ${ }^{37}$

A extensão total do Aqǘfero Guarani é estimada em 1,2 milhóes de quilômetros quadrados $\left(\mathrm{Km}^{2}\right)$, abarcando quatro países: a) $840 \mathrm{~km}$ no Brasil, correspondente a $71 \%$ do total da área abrangida pelo Aqǘfero; b) $225.500 \mathrm{~km}$ na Argentina, ou $19 \%$ da mesma área; c) $71.700 \mathrm{~km}$ no Paraguai ou $6 \%$ da sua área total e; d) $58.500 \mathrm{~km}$ no Uruguai ou $4 \%$ da área do Aqüífero. ${ }^{38}$

Ocupando profundidades de 50 a 1500 metros, o Aqǘfero Guarani contém 50 quatrilhöes de litros de uma das águas mais puras do planeta ${ }^{39}$ e o tempo de renovação destas águas é 300 anos. ${ }^{40}$

Entretanto, inexiste suficiente conhecimento científico sobre os potenciais usos do Sistema Aqüífero Guarani e, ainda, o perigo da ocorrência de danos ambientais transfonteiriços decorrentes da poluição pode ser iminente.

Neste contexto, os princípios da cooperação hídrica, da precaução e a harmonização legislativa em matéria de águas subterrâneas vêm sendo amplamente discutidos entre os países (Brasil, Argentina, Uruguai e Paraguai) que abrigam o Aqüífero.

Em maio de 2003, Brasil, Argentina, Uruguai e Paraguai iniciaram a fase de execução do Projeto de Proteção Ambiental e Gestão Sustentável Integrada do Sistema Aqüúfero Guarani. Este projeto é financiado pelo Fundo Mundial para o Meio Ambiente e pelo Banco Mundial como apoio da Organizaçáo dos Estados Americanos. O objetivo é a criação de um marco legal e institucional para a gestão dos recursos do Aqüífero. ${ }^{41}$

A reunião de Foz do Iguaçu, realizada em janeiro de 2000 , com recursos do governo brasileiro, através da Secretaria de Recursos Hídricos do Ministério do Meio Ambiente (SRH/MMA), foi o marco inicial no qual os Governos da Argentina, Brasil, Paraguai e Uruguai aprovaram o documento conceitual do Projeto ${ }^{42}$, iniciando-se a sua fase de

${ }^{37}$ http://aquiferoguarani.hpg.ig.com.br/descricão2.htm. Acesso em 10.04.2003.

${ }_{38}$ Tal área equivale à extensão dos territórios da Inglaterra. França e Espanha juntos (Rocha, Gerôncio Albuquerque. O Grande Manancial do Cone Sul. In: Revista de Estudos Avançados, volume 11, ñ. 30. São Paulo: Instituto de Estudos Avançados/ USP, 1997, p. 191).

${ }^{3}$ Para se ter uma idéia do que são 50 quatrilhões de litros "por todos os rios do globo correm, ao longo de um ano, 43 quatrithöes de lltros". Ou seja: há mais água no Aqülfero Guarani do que em todos os rios do mundo (Burgierman, Denis Russo. Tem uma esponja aqui dentro. Revista Super interessante, ano 13, $n^{\circ}$. 17, São Paulo: Abril, 1999, p. 62-67).

${ }^{40}$ Rebouças, Aldo da Cunha. Águas Subterrâneas, In: Rebouças, Aldo da Cunha; Braga, Benedito; Tundisi, José Galizia. Águas Doces no Brasil: capital ecológico, uso e conservação. Săo Paulo: Escrituras, 1999. p. 135 
A Aplicaçáo dos Prinćípios da Cooperação Hidurica Intennacional e da Precaução na 423 Gestão das Águas Subterrâneas Transtonteiriças: O Caso do Acquífero Guarani

preparação, que culminou com sua aprovação pelo Fundo Mundial para o Meio Ambiente (GEF) e pelo Banco Mundial em abril de 2002, encontrando-se atualmente em sua fase de execução. Uma Secretaria Geral do Projeto, responsável por coordenar as UNEPs (Unidades Nacionais de Execução do Projeto, que no Brasil é a ANA - Agência Nacional de Águas), iniciou suas atividades em março de $2003 \mathrm{em}$ Montevidéu, Uruguai. ${ }^{43}$

Conforme supra mencionado, o desenvolvimento conjunto e a instrumentalizaçãa de um marco de gestão para o Sistema Aqüífero Guarani constitui o núcleo do Projeto, cujos componentes integrantes da fase de execução são os seguintes: a) expansão e consolidação da base atual do conhecimento científico e técnico do SAG (Sistema Aqüífero Guarani); b) desenvolvimento e instrumentação conjunta de um marco de gestão para o SAG, baseado em um Programa de Ações Estratégicas (PAE) consensuado; c) fomento à participação pública de atores interessados e comunicação sobre educação ambiental; d) avaliação e seguimento do projeto e disseminação dos seus resultados; e) desenvolvimento de medidas para a gestão das águas subterrâneas e para a mitigação de danos, de acordo com as características da tegiăo, em áreas conuns estabelecidas na preparação do Projeto ${ }^{44} ;$ ) avaliação do potencial para utilização da energia geotérmica "limpa" do SAG; e g) coordenação e gestão do Projeto. ${ }^{45}$

Portanto, a incorporaçāo conjunta do Projeto no âmbito do Mercosul representa um promissor exemplo de implementação prática de princípios do Direito Ambiental Intemacional. De um lado, a cooperaçăo hídrica internacional, que pode ser observada no estabelecimento do Programa de Açōes Estratégicas (PAE), o qual prevê deveres e obrigações para a utilização razoável e equuitativa do Aqǘfero. ${ }^{46}$ De outro, o Projeto mostra que a ausência de evidência científica não impede que a poluiçăo seja combatida na sua incipiência e que os recursos naturais sejam utilizados numa base de produção sustentada ${ }^{47}$, ilustrando os genúnos fundamentos do princípio da precaução. De fato, ao buscar uma estratégia de atuação que garanta a gestáo integrada, descentralizada e participativa ${ }^{48}$ do Aqüffero, os países aplicam duas das variadas formas de incidência deste princípio ${ }^{49}:$ 1) promover a participação do povo nos procedimentos decisórios, tomando acessível a informação, favorecendo a pronúncia das populações na gestão da água e 2) incentivar a pesquisa científica para prover informação necessária a evitar danos aos recursos naturais.

\footnotetext{
41 htfp:/www.ana.gov.br/guarani. Acesso em 12.09.2003

$42 \mathrm{http} / / \mathrm{www}$, ana.gov.br/quarani/projeto/sintese. htm. Acesso em 01.09.2003.

43 Atualmente, o Secretario Geral é o brasilejro Luiz Amore, antigo coordenador do projeto no Brasil.

${ }^{44}$ Este componente contempla o desenvolvimento de mecanismos e medidas para a mitigação dos problemas atuais e prioritários em quatro áreas criticas e duas localidades transfonteiriças identificadas dentro da zona do Sistema Aqülfero Guarani: (i) Concórdia na Argentina e Salto no Uruguai; (ii) Rivera no Uruguai e Santana do Livramento no Brasil; (iii) Encarnacion, Ciudad do Este e Canguçu no Paraguai e (iv) Ribeirão Preto no Brasil.

${ }^{43} \mathrm{http} / / \mathrm{www}$. ana.gov.br/guaranifprojeto/sintese.htm. Acesso em 01.09 .2003
} 
Ressalte-se, no ponto, que cerca de 15.000 poços artesianos são conhecidamente explorados na área total do Aqǘfero. A cidade de Ribeirão Preto, no Estado de Sáo Paulo, Brasil, utiliza exclusivamente á água do Aquúfero, o qual já apresenta sinais de poluição nesta área. Logo, tendo sido estabelecido um nexo causal entre a utilização imprópria do SAG em Ribeirão Preto e a poluição do Aqüiffero nesta região, a atuação preventiva é o mecanismo para remediar estes danos. Portanto, nesta área do Aqüífero, onde os perigos são comprovados com evidência científica suficiente, reconhece-se a concreta aplicação do princípio da prevenção, ainda que parte da doutrina não o diferencie da precaução.

\section{c. A Harmonização Legislativa em Matéria de Águas Subterrâneas nos} Países do Mercosul:

Os princípios supra analisados também são capazes de orientar a criação de um modelo para a gestāo coordenada do Sistema Aqüífero Guarani, que inclua arranjos jurídicos e intercâmbio de dados, conforme previsto no Projeto. No ponto, ressaltese que elaboração deste modelo tende a culminar na harmonização legislativa em matéria de águas subterrâneas nos países do Mercosul.

A hamonização consiste na aproximação entre as legislaçoes dos Estados. partes, visando à redução das principais desigualdades existentes, com a determinação de critérios, princípios, requisitos mínimos comuns a serem seguidos pelos Estados-membros ${ }^{50}$, sem que haja a imposição de que as legislações tornemse idênticas em todos os aspectos (senão passaria a ser a chamada unificação). ${ }^{51}$

Assim, torna-se pertinente uma análise comparativa do tratamento das águas subterrâneas nas Constituições e legislação infraconstitucional de cada um dos países

\footnotetext{
${ }^{45} \mathrm{O}$ componente 2 do projeto estabelece um marco técrico, institucional, financeiro e juridico, acordado para a gestão do Sistema Aqüifero Guarani, incluindo: (i) a harmonizaçăo e o melhoramento de redes de compilação e difusão de dados; (ii) a criação de um sistema de administração de dados; (iii) estabelecimento de acordos institucionais conjuntos para a gestão do Sistema Aquifero Guarani e (iv) formulação de estratégias que levem a integração e otimização das inciativas e propostas para o desenvolvimento dentro da reglão do Sistema Aqüifero Guarani. Para um visão completa e detaihada dos sete componentes do Projeto, veja http:/www.ana.gov.br/ quaraniforojeto/sintese.htm. Acesso em 01.09.2003.

${ }_{47}$ Rehbinder, Eckard. O direito do ambiente na Alemanha. In: Amaral, Diogo de Freitas do (Org.). Direito do ambiente. Oeiras: INA, 1994, p. 257.

48 O componente 3 do Projeto prescreve participação pública, educação e comunicação na gestäo integrada do recurso hídrico, estabelecendo a participação prática de partes interessadas na tomada de decisões que afetam o Sistema Aqüffero Guarani por melo de programas educativos e informativos. O Fundo do Sistema Aqüifero Guarani para a Cidadania designado para participar no financiamento de açðes de organizaçōes governamentals e instituições acadêmicas é um aspecto integral deste componente. http:// www.ana.gov.br/quarani/projeto/sintese, htm. Acesso em 01.09.2003.

49 Silva, Luis Praxedes Vieria da. Principio da Precaução e Recursos Hidricos. In: Direito, Água e Vida/ Law, Water and The Web of Life. Org: Benjamin, Artonio Herman, Säo Paulo: Imprensa Oficial, 2003, Vol. 1, p. 709-717.
} 
A Aplicação dos Princípios da Cooperação Hídrica Intennacional e da Precaução na 425 Gestão das Águas Subterrâneas Transfonteiriças: $\bigcirc$ Caso do Aquíf́ero Guarani signatários do Projeto. O objetivo é antever a viabilidade da harmonização da legislação sobre águas no contexto do Mercosul.

Na esfera constitucional, Argentina, Uruguai e Paraguai não se referem expressamente às águas como faz a Carta Magna Brasileira. As Constituiçóes destes países tratam de temas como o direito fundamental ao ambiente saudável e à qualidade de vida ${ }^{52}$, o desenvolvimento sustentáve ${ }^{53}$, a reparação do dano ambiental ${ }^{54}$ e o direito de informação ambiental ${ }^{55}$, sempre em forma de princípios ${ }^{56}$.

A Constituição Brasileira, por sua vez, coloca as águas subterrâneas como pertencentes ao domínio público. Nos termos do art. 26, inciso I, "inchuem-se entre os bens dos Estados as águas superficiais ou subterrâneas, fluentes, emergentes e em depósito, ressaluadas, neste caso, na forma da lei, as decorrentes de obras da União".

Suscita dúvida a quem pertencem estas águas quando se estendem pelo território de mais de um Estado ou país, já que o art. 20, inciso III, prevê que "são bens da Uniäo, os lagos, rios e quaisquer correntes de água em terrenos de seu domínio, ou que banhem mais de um Estado, sirvam de limites com outros paises, ou se estendam a territónio estrangeiro ou dele provenham, bem como os terrenos marginais e as praias fluviais".

Uma interpretação literal dos dois artigos diria que se as águas subterrâneas não foram referidas no art. 20, que trata dos bens da Uniăo, as águas subterrâneas transfonteiriças são bens dos Estados. ${ }^{57}$

No entanto, data vênia, percebe-se que o art. 20 não menciona as águas subterrâneas que transbordam as fronteiras do Brasil, como o Aqüffero Guarani. $O$ art. 26, por sua vez, reconhece como sendo bens da União quaisquer cortentes de água que banhem mais de um Estado ou sirvam de limites com outros países. Este conceito se encaixa perfeitamente no Aqüifero Guarani, o qual banha sete Estados Brasileiros (MS, MG, GO, SP, PR, SC e RS) e serve de limites com outros três países. No ponto, é de se mencionar o conceito de águas subtertâneas adotado pela

\footnotetext{
50 Prado, Alessandra Rapassi Mascarenhas. Mercosul e o Crime de Polulção das Águas. In: Revista Brasileira de Ciencias Criminais $\pi^{\circ}$. 44, p. 169-197.

5t A Declaração de Tranco, resultante da primeira Reuniäo de Ministros de meio Ambiente do Mercosul, dispöe nesse sentido: "harmonizar não implica estabelecer uma legislação única, senão eliminar eventuais assimetrias e dirimir divergências".

${ }^{31}$ artigos $6^{\circ}$ e $7^{\circ}$. da Constituição Nacional do Paraguai, art. 41 da Constituição Argentina e art. 225 da Constituição do Brasil.

52 art. 41 da Constituição Nacional da Argentina e art. 225 da Constituição do Brasil.

${ }^{53}$ art. $7^{\circ}$. da Constituição Nacional do Paraguai, art. 41 da Constituição Argentina e art. 170 da Constituiçăo do Brasil.

${ }^{54}$ art. 28 da Constituiçâo Nacional do Paraguai e art. 41 da Constituição Argentina.

55 Fakkenberg, Luisa. O Desafio da Integração na área do Direito Ambiental. In: Contratos Internacionais e o Direito Econômico no Mercosul. Org: Casella, Paulo Borba, Săo Paulo, LTR, 1994, p. 235-255.

${ }^{56}$ Silva, Solange Teles da. Aspectos Juridicos das Águas Subterrâneas. In: Revista de Direitos Difusos, vol. 16, nov,-dez./2002, p. 2165-2173.
} 
Resolução no 15 do Conselho Nacional de Recursos Hídricos. Em seu art, 1a, inc. I, águas subterrâneas estão definidas como "aquelas que correm naturalmente ou artificialmente no subsolo" ${ }^{\text {58. }}$. Mais uma vez, confirma-se que águas subtertâneas são cortentes de água, termo mencionado no art. 26 da Magna Carta.

Resta demonstrado, pois, que os dois artigos constitucionais guardam diferença limitada à sua forma de redação: o constituinte optou pelo termo "correntes de água" no artigo 20 e "águas subterrâneas" no artigo 26. Entretanto, expressamente delimitou, no artigo 20, as características pertencentes às correntes de água sob o domínio da União, as quais, conforme mencionado, subsumem-se contextualmente àquelas do Sistema Aqüifero Guarani. ${ }^{59}$

Em verdade, não há como justificar o fato de lagos e rios transfonteiriços pertencerem à União e o que está abaixo de sua superfície com os mesmos requisitos, ou seja, banhar mais de um Estado e servir de limites entre países, ser de domínio dos Estados ${ }^{60}$. Isso porque a gestão das águas subterrâneas deve ser feita de forma integrada com as águas superficiais e a gestão do solo. Caso contrário, os Estados poderão, en tese, extraílas à vontade do seu território ${ }^{6 j}$. Com isso, abre-se campo para conflitos e para a eventual exaustão dos aqüfferos, pelo menos até que lei federal venha a disciplinar critérios de outorga do direito de uso destas águas.

Portanto, a interpretação constitucional de acordo com o princípio da cooperação e da gestão integrada das águas é a de que as águas subterrâneas confinadas no território de um único Estado pertencem ao domínio estatal e as transfonteiriças, seja entre Estados ou países, pertencem à Uniāo.

Esta discussão quanto ao domínio das águas subterrâneas não se repete nos outros países em análise. Em que pese o Paraguai não dispor de uma lei sobre recursos hídricos ${ }^{62}$, nos demais países, a matéria encontra-se de forma mais clara no plano infraconstitucional.

Na Argentina, há um capítulo específico sobre águas subterrâneas nos Códigos Provinciais. De regra, dispóe-se que águas subterrâneas são de domínio público das províncias, sendo, em tese, inalienável a sua propriedade ${ }^{63}$, estando classificadas entre as

\footnotetext{
57 Siva, Solange Teles da. Regime Juridico das Águas Subterrâneas. In: Direito, Água e Vidal Law ,Water and The Web of Life. Org: Benjamin, Antonio Herman, São Paulo: Imprensa Oficial, 2003, vol. 1, p. 817-832.

${ }^{58}$ Contribuição do Prof. Dr. Antônio Herman Benjamin durante os debates orais realizados na apresentaçäo do presente artigo na 24th Annual ILASSA Student Conference na University of Texas at Austin, U.S.A.

59 Palestra proferida pelo Prof. Dr. Antonio Herman Benjamin no Forum Internacional das Águas, Oficina 04: "Legislaçăo das Águas", reałizado em Porto Alegre, RS, Brasil, no período de 08 a 11 de outubro de 2003.

"Ao Pompeu, Cid Tomanik. Recursos hidricos na Constituiçăo de 1988. In: Revista de Direito Administrativo, $n^{\circ}$. 186, out/dez/91, p. 11-13.

o1 Um anteprojeto de lei de águas cujo objetivo é definir um marco legal e institucional para a admnistraçăo dos recursos hidricos do Paragual encontra-se em elaboração pela Secretaria del Amblente. In: www. seam.gov.py. Acesso em 10.12.2003.
} 
A Aplicação dos Princípios da Cooperação Hídrica Internacional e da Precaução na 427 Gestão das Águas Subtertâneas Transfonteiriças: $O$ Caso do Aqüítero Guarani coisas fora do comércio, assim, supostamente, vedada a sua comercialização. ${ }^{64}$ A exceção a esta regra são as águas que, segundo o Código Civil Argentino, pertencem ao domínio privado ${ }^{65}$ Porém, mesmo as de domínio privado estão sujeitas ao controle e restrições em função do interesse público. ${ }^{66}$

No Uruguai, também há um capítulo específico para o trato destas águas, segundo o qual integram o domínio público todas as águas subterrâneas que não estiverem incorporadas ao patrimônio dos particulares quando da entrada em vigor do Código de Águas, Ley no 14.859 de $1978,{ }^{67}$ e que se encontrem em terreno de domínio público ou fiscal. ${ }^{68}$

Quanto aos direito de uso destas águas, o Brasil, ao contrário da Argentina, reconhece expressamente a água como bem dotado de valor econômico ${ }^{69}$ e prevê a cobrança pelo seu uso a fim de incentivar sua racionalizaçăo e dar ao usuário uma indicação de seu real valor. ${ }^{70} \mathrm{O}$ valor pago ao fim de cada mês à companhía de saneamento refere-se ao tratamento e à distribuição da água e à coleta de esgoto, e não, ao uso do líquido em si, que ainda é de graça. A extração de água de aqüífero subterrâneo para consumo final ou insumo no processo produtivo está sujeita à outorga pelo Poder Público."

Na Argentina, o uso das águas subterrâneas em terrenos privados não requer concessão nem permissão ${ }^{n}$ quando, entre outros casos, se destine à satisfação de necessidades básicas como bebida e higiene humana. ${ }^{73}$ Qualquer outro uso requer permissão e concessão da autoridade provincial ${ }^{14}$ com a respectiva cobrança.

No Uruguai, o proprietário de um terreno o será também das águas subterrâneas que dele se extraiam. Entretanto, a extração está sujeita à autorizaçăo do Ministério competente quando se trate de terreno privado e sujeita à concessão e cobrança de contribuições pelo uso quando se trate de terreno público ou fiscal ${ }^{75}$. Também a extração nos terrenos privados não está sujeita à autorização se feita exclusivamente com o intuito de satisfazer necessidades de bebida, higiene e usos domésticos ${ }^{76}$.

Diante deste panorama sobre o tratamento das águas subterrâneas nos países que abrigam o Aqǘfero Guarani aliado ao recém assinado Projeto para Gestão Sustentável

\footnotetext{
$\overline{62}$ arts. $1^{\circ}$. e $7^{\circ}$. da Ley $n^{\circ} 3230$, Codigo de Aguas de la Provincia del Chaco de $1987 \mathrm{c} / \mathrm{c} 0$ capitulo VIl da Ley de Aguas Provincia de Misiones de 1983.

63 art. $4^{\circ}$., Ley $n^{\circ} 3230$, Codigo de Aguas de la Provincia del Chaco.

64 art. $8^{\circ}$., Codigo de Aguas de la Provincia del Chaco.

${ }^{65}$ art. $8^{\circ}$., Codigo de Aguas de la Provincia del Chaco.

${ }^{66}$ art. 15, Codigo de Aguas, Ley $7^{\circ} 14.859$ de 1978.

${ }^{67}$ art. 42, Codigo de Aguas, Ley $n^{\circ} 14.859$ de 1978.

${ }^{68}$ art. $1^{\circ}$., inc. II da Lei $n^{\circ}$. 9433/1997.

${ }^{69}$ Seção IV - Lei no. 9433/1997.

${ }^{70}$ Seção 11 - Lel $n^{\circ}$. 9433/1997.

71 art. 45, Ley $\pi^{\circ} 3230$, Codigo de Aguas de la Provincia del Chaco.

${ }^{72}$ art 79 , Ley $n^{\circ} 3230$. Codigo de Aguas de la Provincia del Chaco.
} 
Integrada destas águas, conclui-se que a harmonização jurídica não se apresenta como fim absoluto ou que se esgote em si mesma. Ela seria um instrumento para assegurar grau mínimo indispensável de aproximação entre dispositivos legais, regulamentares e administrativos dos Estados-partes.

Brasil, Argentina, Uruguai e Paraguai adotam um regime jurídico de Direito Público em matéria de águas subterrâneas. Dissocia-se, pois, o direito de propriedade do direito de uso, que passa a ser submetido a regras especiais por motivos de interesse geral.

Neste quadro, a harmonização seria limitada às matétias nas quais a diversidade de dispositivos nacionais poderia acarretar obstáculos à exploração sustentada do Aqüŕfero entre os países do Mercado Comum. Não se pode negar que fatores como a possibilidade de comércio internacional de água, os efeitos das mudanças climáticas ou ainda o crescimento demográfico nos países provocarão uma intensificação das pressões sobre o Aqüúfero Guarani. Assim, este regime jurídico de Direito Público sobre as águas subterrâneas justifica-se na medida em que o Poder Público assume o papel de gestor da preservação deste bem, assegurando a proteção e o equilíbrio dos ecossistemas e dirimindo eventuais conflitos entre os usuários. ${ }^{77}$ Ademais, o regime de dominialidade pública das águas deve evoluir, conduzindo a coletividade, ou seja, todos os cidadãos a assumirem a obrigação de conservação e preservação do Aqüiffero Guatani.

4. Conclusões Articuladas:

1. A cooperação hídrica internacional, cujos princípios estão explicitados ná Convenção das Naçóes Unidas sobre a Utilização dos Cursos de Água Internacionais para fins distintos da Navegação, está sendo implementada entre os páses do Mercado Comum do Sul e deve nortear as ações de execução do Projeto para Proteçāo Ambiental e Gestão Sustentável Integrada do Sistema Aqüúfero Guarani.

2. O princípio da precaução, o qual não exige certeza científica sobre os riscos de dano ao meio ambiente para a tomada de medidas a evitá-lo, está também norteando as ações para a criação de um marco institucional e legal para a gestão sustentada do Aqǘf́ero.

\footnotetext{
$\overline{73}$ art. 47, Ley $n^{\circ} 3230$, Codigo de Aguas de la Provincia del Chaco.

74 at. 46 e 167 Ley $n^{\circ} 14859$, Codigo de Aguas.

75 art. 49 Ley $n^{\circ} 14859$, Codigo de Aguas.

${ }^{76}$ Silva, Solange Teles da. Regime Juridico das Águas Subterrāneas, In: Direito, Água e Vidal Law, Water and The Web of Life. Org: Benjamin, Antonio Herman, São Paulo: Imprensa Oficial, 2003, Vol. 1, p. 817-832.

77 Conforme já exposto na Constituição da República Federativa do Brasil, artigo $225, \S 1^{\circ}$., c/c artigo $4^{\circ}$., II, $V, V \|,|X, 23,1, V I| X,, X \mid$ e parágrafo único, $24, V 1, \S \S 1^{\circ}, 2^{\circ}, 25,30, \mid, 32,170, V I_{\text {r }}$ 200,II, V.VI, Agenda 21, Caps. 17 e 18. Carta Européia da Águas, Princípio 12.
} 
A Aplicação dos Princípios da Cooperação Hídrica Intemacional e da Precauţão na 429 Gestão das Águas Subterrâneas Transfonteiriças: $O$ Caso do Aquíftero Guarani

3. Ambos os princípios mostram-se apropriados para aplicação na área do Aqǘífero Guarani, onde a múltipla e seqüencial utilização do recurso precisa ser administrada dentro do território geopolítico.

4. A harmonizaçãa da legislação sobre águas dos países do Mercosul pode ser efetivada, tendo em vista que Brasil, Argentina, Uruguai e Paraguai adotam um regime jurídico de Direito Público em matéria de águas subterrâneas. Neste caso, a harmonização seria um instrumento de implementação do Projeto e se limitaria às matérias nas quais a diversividade de dispositivos nacionais acarreta obstáculos à gestão sustentada do Aqüífero. Por sua vez, o princípio da cooperação hídrica internacional ${ }^{78}$ e da precaução norteariam as alterações nas legislações nacionais.

5. Portanto, a água é um elemento essencial dos processos de integração ${ }^{79}$, pois mais do que a sua funçăo de separar fronteiras, ela exerce uma função integradora ou aglutinante, ou seja, rios, lagos e correntes de água subterrânea têm sido utilizados, ao longo da história, para produzir energia, para consumo humano, para a agricultura, enfim para utilização de comunidades inteiras como um bem de uso comum de todos.

78 lza, Alejandro. Desafios para la conservación de los recursos hidricos en los procesos de integración. In: Direito, Agua e Vida/ Law, Water and The Web of Life. Org: Benjamin, Antonio Herman, São Pauło: Imprensa Oficial, 2003, Vol. 1, p. 27-39. 